\title{
Incorporating Green Chemistry Concepts into the Senior Secondary School Curriculum
}

\author{
${ }^{1}$ John O. Agbayewa, ${ }^{1}$ Kunle O. Oloruntegbe, ${ }^{2}$ Ese M. Alake \\ ${ }^{1}$ Science and Technical Education Integrated Science, Adekunle Ajasin University, Nigeria \\ ${ }^{2}$ College of Education, Akungba-Akoko, Nigeria
}

\begin{abstract}
This paper aims at incorporating the green chemistry concepts into the senior secondary or high school chemistry curriculum. Researches and training in this all important area had been targeted towards universities and industries with little or no effort at inculcating the principles of green chemistry in the younger generation who are the future of every nation. Using the Nigerian Senior Secondary Curriculum as a case study for the proposed incorporation, it was observed that several of the contents could be made to incorporate the principles of green chemistry without much overburdening. It is the opinion of the authors that this effort will yield a long term benefit of producing chemists and industrialists who would enforce greener policies and work for safer environment. This would in turn help to achieve sustainable environment devoid of prevalent environmental problems that impact negatively on earth's biocapacity.
\end{abstract}

\section{Introduction}

The composition of the Earth's atmosphere is undergoing an unprecedented change, largely as a result of human activities, industrial development, fossil fuel burning, deforestation and agricultural practices. These have led to an increase in the atmospheric concentration of pollutant gases. Such gases include carbon (iv) oxide and methane that are responsible for the greenhouse effect. The increase in concentration of these gases could have far reaching consequences. Lapkin \& Constable [7] opined that the scientific estimates of these gases indicate a rise in the global mean temperature of between $1.40 \mathrm{C}$ and $5.80 \mathrm{C}$ over the next 100 years.

The above is confirmed by the findings of [1] which stated that 400 million tons of $\mathrm{CO} 2$ is released yearly through gas flaring. Most oil communities therefore live with gas stacks that flare gas 24 hours a day at temperature of 13-14,000 degrees Celsius. It is obvious that a temperature rise of this magnitude over such a relatively short space of time would impact negatively on earth's biocapacity. Water in streams, rivers and seas is not spared of pollutants from untreated affluent form chemical industries. Besides all these, there are other socialeconomic and domestic issues and practices that necessitate the early introduction of green chemistry principles into the nations' educational systems, particularly at the secondary or high school level. These practices range from improper waste and sewage disposal in the communities; improper disposal of spent chemicals in schools and industries; bush burning for agricultural purposes and killing of animals for sale, using toxic chemicals to kill fish; and littering the landscape from the huge waste generated from home made and imported food and materials like computer and other chemical industrial products and technological devices.

Green chemistry is the science of creating safe, energy efficient and non-toxic products and processes and offers a concrete path towards solving the environmental problems our society faces today [8]. It is the practice of chemical science and manufacturing in a manner that is sustainable, safe, and non-polluting and that consumes minimum amounts of materials and energy while producing little or no waste material. The practice of green chemistry begins with recognition that the production, processing, use, and eventual disposal of chemical products may cause harm when performed incorrectly.

Those who practice green chemistry recognize that they are responsible for any effects on the world that their chemicals or chemical processes may have. Basically, green chemistry harnesses a vast body of chemical knowledge and applies it to the production, use, and ultimate disposal of chemicals in a way that minimizes consumption of materials, exposure of living organisms, including humans, to toxic substances, and damage to the environment. And it does so in a manner that is economically feasible and cost effective. The concept of green chemistry has therefore received more attention in the past two decades but often at university and industrial level of researches. Hence, there is the need to incorporate the concepts to lower level chemistry so as to catch them young. Characterized by 3Rs of Reduce, Reuse and Recycle of waste, green chemistry is towards supporting the environment to support us (man). In one sense, it is the most efficient possible practice of chemistry and the least costly when all of the costs of the practice of chemistry, including hazards and potential environmental damage are taken into account. In recent times, chemical industries have advanced so much, producing bio and nonbiodegradable materials for our comfort and luxuries. However, hese all have resulted in harm to the environment and living things, including humans. It 
is like a case of gains in chemical science being cancelled by the loss due to the abuse of it.

Green chemistry, however, came as the solution to the problem of waste production by encouraging chemical industries to make their reactions and products environmentally benign. Much research had been and is still being carried out generally on how to promote green chemistry and protect the environment $[4,5,7,6]$. Several awards and grants had been made - Green Chemistry STAR Grants [11], many workshops have been held, while journals of clean processes and products have devoted sections to green chemistry publications and information. In United States, green chemistry is seen as a common research program resulting from interdisciplinary cooperation of university teams, independent research groups, industry, scientific societies and governmental agencies, with each having their own programs devoted to decreasing pollution [13], with green catalysis and reagents, biocatalysis, selective activation, alternative solvents, renewable sources of chemicals and having research policy as the central themes of discussions. Many chemical industries have been sensitized on the need to prevent waste, design safer chemical processes, use renewable feedstocks, use safer solvents and reaction conditions, analyze in real time to prevent pollution, and minimize the potential for accidents as stipulated in the twelve principles of green chemistry shown below. These efforts were targeted only at the university level with little or no attention paid to the lower levels as far as green chemistry is concern, hence, the advocacy.

The twelve green chemistry principles as summarized and contained in [2] are:

1. Prevent waste

2.Achieve atom economy: maximize incorporation

3. Use less hazardous synthesis steps

4. Design safer chemicals

5. Use safer solvents and auxiliaries

6. Design for energy efficiency

7. Use renewable feedstocks

8. Reduce derivatives

9.Catalytic reagents are superior to stoichiometric

10. Design for degradation

11.Real-time analysis for pollution prevention

12.Inherently safer chemistry prevents accidents

How many chemical industries are practicing these principles in their operations? If industries are not practicing them, it is perhaps because the present crops of chemists are not trained in them. Popularizing green chemistry will require bringing the principles down, not only to the level of university undergraduates, but also to the high school level. It is the high school science students of today that will become tomorrow chemists that will eventually man the chemical industries. There is therefore, the need to foster such training to younger generations by greening the secondary school chemistry curriculum worldwide.

This paper aims at advocating the incorporating of green principles and sustainability chemistry into the existing senior secondary or high school chemistry curriculum globally, and particularly in the developing nations where there have been serious environmental problems with little or no attempt at inculcating green chemistry principles at any level of the nations educational system. The Nigerian senior secondary school chemistry curriculum is taken as a case study for this advocacy.

\section{Current Nigerian SS Chemistry Curriculum}

The Nigerian Senior Secondary (SS) Chemistry Curriculum covers three classes, Senior Secondary classes $1-3$ and has been developed around four themes: Chemistry and Industry, the Chemical World, Chemistry and Environment and the Chemistry of Life [9]. In selecting the contents, three major issues shaping the development of nations worldwide and influencing the world of knowledge today were identified [9]. These are globalization, information/communication technology and entrepreneurship. The desire to be identified with contemporary development worldwide has called for the organization of the contents of the curriculum around the four themes in Nigeria. Such that the curriculum is packaged with content, that leads to self-actualization by students, self-employment and contribution of individuals to the unity of the nation. In addition, the curriculum content focuses on practical activities with emphasis on the use of locally available materials for such activities and experimentation. The above is with the aim of imbibing in the student/ learner with the spirit of inquiry that allow for decisions related to science and society. The curriculum, if effectively implemented, will enable the learner achieve his/her maximum potential in the subject of chemistry and its various applications. The major topics covered in four themes in the three classes are summarized in the table 1 below.

From the table 1 the chemistry syllabus in the secondary school therefore is the learning experience (topics) that the student is exposed to at a particular level and time in order to attain the set goals. The syllabus or topics in the subject is arranged in a logical sequence for coverage in order that the students which the syllabus is meant can pass specific examination and it is a teaching syllabi consisting of outline of work planned to be done within a period of 3 years.

The topics are arranged in a logical sequence according to the relationship between the various topics which covers contents of examination 
Table 1. Summary of Nigerian SS1-3 Chemistry Syllabus

\begin{tabular}{|l|l|l|l|}
\hline $\begin{array}{l}\text { THEME/CL } \\
\text { ASS }\end{array}$ & \multicolumn{1}{|c|}{ SS1 SS2 } & SS3 \\
\hline $\begin{array}{l}\text { Chemistry } \\
\text { and industry }\end{array}$ & Chemistry and industries & $\begin{array}{l}\text { Periodic table, chemical } \\
\text { reactions, Mass volume } \\
\text { relationship }\end{array}$ & $\begin{array}{l}\text { Quantitative and } \\
\text { qualitative analysis }\end{array}$ \\
\hline \hline $\begin{array}{l}\text { The chemical } \\
\text { world }\end{array}$ & $\begin{array}{l}\text { Introduction to chemistry, } \\
\text { Particulate nature of matter, } \\
\text { Symbols, formulae and equations, } \\
\text { Chemical combination, Gas laws }\end{array}$ & $\begin{array}{l}\text { Acid-base reactions, } \\
\text { Water, Air, Hydrogen, } \\
\text { Nitrogen, Sulphur }\end{array}$ & $\begin{array}{l}\text { Petroleum Mental and their } \\
\text { compound iron Ethical, legal and } \\
\text { social issue }\end{array}$ \\
\hline $\begin{array}{l}\text { Chemistry } \\
\text { and } \\
\text { environment }\end{array}$ & $\begin{array}{l}\text { Standard separation techniques for } \\
\text { mixtures Acids bases and salt } \\
\text { Water }\end{array}$ & $\begin{array}{l}\text { Oxidation-reduction(redox) } \\
\text { Reaction Ionic theory } \\
\text { Electrolysis }\end{array}$ & Hydrocarbons and Alkanols \\
\hline $\begin{array}{l}\text { The chemistry } \\
\text { of life }\end{array}$ & Carbon and its compounds & $\begin{array}{l}\text { Fats and oil } \\
\text { Soap and } \\
\text { detergent } \\
\text { Giants molecules }\end{array}$ \\
\hline
\end{tabular}

realizing the limitation of low, medium and high ability students.

No wonder researchers have opined that science contents are too strongly driven and focused too exclusively on scientific knowledge as a result such lessons are not popular [11]. Students often therefore fail to see the relevance of science (chemistry) and they often do not see the connection with their everyday life or their future. The content of chemistry in Nigeria senior secondary schools shows very few topics that are green chemistry compliant.

\section{Why the incorporation}

In order to deal with the enormous damage to the environment due to activities of chemical industries and move within the specific and broader educational contexts of maintaining the environment to better support us, there is the need to integrate green chemistry in the senior secondary school curriculum.

It is now very obvious that chemical science must be turned away from emphasis upon the exploitation of limited resources and the production of increasing amounts of products that ultimately end up as waste and toward the application of chemistry in ways that provide for human needs without damaging the Earth support system upon which all living things depend. Chemical science and industry had to move steadily in the direction of environmental friendliness and resource sustainability. The practice of chemistry in a manner that maximizes its benefits while eliminating or at least greatly reducing its adverse impacts is good justification for green chemistry. In addition to the above, there are other

justifications for the incorporation of green chemistry into the nations' education system generally and secondary education in particular. Four fundamental reasons were advanced in "Science and
Engineering Indicators" which are necessity, responsibility, interest, and efficiency.

Green chemistry is necessary chemistry. As things currently stand, human consumptions are not a sustainable process because all results in waste production. This problem will be exacerbated as developing countries industrialize and our fossil fuel resources become depleted. Furthermore, recent discoveries about eco-toxic effects such as endocrine disruption and carcinogenic materials from air, land and water waste have made it clear that synthetic chemicals released into the environments are disrupting world ecosystems in new and terrifying ways. An approach including the green chemistry principles of sustainability and the use and synthesis of benign substances whenever possible will help mitigate the effects of man-made interference in the natural environment.

Green chemistry is responsible chemistry that enhances environmental support. Many workers in the chemical field, in either academic or industrial settings, have had accidents with the potential to cause long-term damage to their health and wellbeing. As chemical workers, however, we have knowingly chosen to accept the risks of working in a chemical laboratory and typically have the opportunity to protect ourselves by gathering as much information about the potential risks as possible. The general public, however, has not chosen to accept the same risks, hence the need to help youngsters who are the future of any nation to be well informed.

Green chemistry is interesting chemistry. Few analogues to traditional chemical practices exist using green alternatives, and the development of these analogues will provide new research areas for young chemists and chemical engineers. Furthermore, green chemistry requires a large amount of cross disciplinary interaction, which will 
lead to new developments as researchers in differing disciplines interact with one another.

Green chemistry is efficient chemistry. The development of benign, non-wasteful alternatives to traditional chemistry has the potential to save industrial and academic interests large amounts of money due to decreased regulation compliance costs and disposal costs. Furthermore, the basic decrease in process hazards drastically increases both worker and consumer safety. Green chemistry is necessary, responsible, interesting, efficient, and above all, it is a good chemistry.

\section{The Proposed Integration}

The SS chemistry syllabus was further broken down to performance objectives, contents, teachers and learners activities, materials and evaluation. In this paper only a few sample of the integration made in the performance objectives area are shown with my addition or the proposed addition in italics.

SS1 Theme 1 The chemical world, Topic Symbols, formulae and equations. to:

By the end of the lesson students should be able

1. State the symbols of the first 20 elements and other common elements;

Green chemistry objectives

2. Discuss some of the green aspects of the first twenty elements and how they relate to sustainability. Such elements include oxygen - the breath of life, carbon - the element of life, nitrogen, hydrogen and organic compounds formed from them, cycles and sustainability.

3. Distinguish between elements, compounds, and mixtures

4. Write chemical formulae and chemical equations

5. Calculate between the empirical and molecular formulae of compound

6. Illustrate that matter is neither created nor destroyed

7. State and illustrate the laws of constant composition and multiple proportions

SS2 Theme 3. The chemical world, Topic 1 Acids, bases and salts. Performance objectives: Students should be able to:

1. Define acids, bases, and salts;

2. Identify acids and bases;

3. Describe the nature of proton in an aqueous solution;

4. Explain neutralization reactions;

5. Explain how an acid-base indicator works;

6. Use $\mathrm{pH}$ as a scale and discuss the importance of the $\mathrm{pH}$ value;

7. Identify and prepare salts (normal, acidic and basic);

Green chemistry objectives

8. State properties of salts;
9. State the rules of solubility of salts in water;

10. Identify green alternatives to strong acids;

11. Relate the production of ethanoic acid through a green process using biological reactions acting upon renewable biomass raw materials; 12. Explain the reclamation and recycling of acids particularly spent and hazardous ones.

SS3 Theme 1. The chemical world, Topic 1 Petroleum. Performance objectives:

Students should be able to:

1. Explain the origin and state the composition of crude oil (petroleum)

2. Discuss the exploration of and drilling for crude oil in Nigeria

3. Explain the fractional distillation of petroleum and list the major fractions (products)

4. List the location of Nigerian refineries

5. Explain the terms cracking and reforming

6. Discuss the use of petrochemicals as starting materials of organic synthesis leading to organic compounds like plastics, synthetic rubber, drugs, insecticides, detergents, fibres, etc.

7. Explain the use of octane numbers in determining the quality of petrol

8. Explain the occurrence, packaging and uses of natural gases

Green chemistry objectives

9. State the economic importance of petroleum;

10. Explain the negative aspect of petroleum refining like oil spill, seismic activities, soil degradation, water pollution and their effects on flora and fauna;

11. Explain the pollution effect of gas flaring in Nigeria;

12. Discuss how to achieve and sustain lasting relationship between the multinational oil companies and the host communities.

Under metals and the compounds the following objectives are added. Students should be able to:

3. Explain that some metal ions in water form humic substances that are useful like $\mathrm{Fe}++$ and other that are carcinogens (cancer causing agents); 4. Explain that metal ores are finite in nature and that there is the need to recycle used ones. This kind of addition representing the integration spans the entire contents of the curriculum.

\section{Benefits}

As noted by Braun et al [3] and Oloruntegbe [10] "Green Chemistry is not intended to be a solo discipline, but rather a means for conducting science in a responsible manner" The objective is not meant to replace existing class materials or be taught as a separate section altogether. Instead, existing materials should be taught in a new way to incorporate key concepts into the curriculum to make chemistry inherently green. We should also bear in mind that the present curriculum material is already 
overburdened, crying for trimming down. The major benefit of catching them young is to make the youngsters imbibe environmental consciousness and accounting early in life. These youngsters could grow to become chemists who will make sure the 12 principles of green chemistry are adopted in the industries they find themselves working. In addition to this, the African chemists would be able to uphold the 13 principles of Greener Africa. (See appendix for 13 principles of Greener Africa).

\section{Conclusion and Recommendations}

From the ongoing discussion it can be seen that green chemistry could be integrated into the SS chemistry curriculum. The existing curriculum could be reviewed to accommodate this. More refinement can be done at that point. It is therefore recommended that stakeholders in education, industries and environmental protection agency take a look at this proposal for implementation. There is a long term benefit of achieving sustainable environment devoid of prevalent environmental problems occasioned by incessant climate change and other greenhouse effects.

\section{References}

[1] Amanze-Nwachukwu, C (2008) Nigeria, Norway seal deal on gas flaring, oil spill. http://www.thisdayonline.com/nview.php?id+99813. Accessed January 9, 2012.

[2] Anastas, P.T. and Warner, J.C. (2000). Principles of Green Chemistry, Green Chemistry: Theory and Practice.

[3] Braun, D., Charney, R., Clarengs, A., Farrugia, L., Kitchens, C. Lisawski, C. Naistat, D \& O'Neil, A. (2006).Completing our Education: Green Chemistry in the Curriculum. Journal of Chemical Education, 83.

[4] Busch, D., (2000). Greening Across the Chemistry Curriculum. US Scranton Green Chemistry.

[5] Collins, F.S., Gray, G.M. \& Bucher, J.R., (2008). Toxicology: Transforming Environmental Protection. Science, 319(5865), 906-907.

[6] Hoag, H., (2009). The Greening of Chemistry. Chemical Heritage Newsmagazine, 27(2).

[7] Lapkin, A. \& Constable, D.J.C., (Ed.). (2008), Green Chemistry Metrics - Measuring and Monitoring Sustainable Processes. West Sussex, United Kingdom: John Wiley \& Sons.

[8] Mazzali, T., Morin, A. \& Paquette, A., (2009). Analysis of Green Chemistry and Computational Toxicology. US Environmentral Protection Agency, National Center for Environmental Research.
[9] Nigerian Educational Research and Development Council, NERDC (2007). Federal Ministry of Education Senior Secondary Education Curriculum Chemistry for SS1-3.

[10] Oloruntegbe, K.O., (2012). Achieving Green Sustainable Chemistry and Environmental Accounting through SS Chemistry Organic Curriculum, A Symposium presented at the 22nd Biennial Conference on Chemical Education at Pennsylvania State University, USA on August 1-4, 2012.

[11] Owen and Buchdahl, (2002), Owen P. and Buchdahl J. (2002) Climate change and ozone depletion Teaching Pack KS3/4. Atmosphere, climate and Environment Manchester. http://www.ace.mmu.ac.uk/

[12] Pan African Chemistry Network, (2011), Wealth Not Waste: Green Science and Engineering for Sustainable Growth in Africa.

[13] Wardencki W., Curyo J., Namieoenik J., (2005) Green chemistry - Current and Future Issues Polish Journal of Environmental Studies Vol. 14,(4), 389-395.

\section{Appendix}

Thirteen principles for a Greener Africa [12]
G - Generate Wealth not Waste
R - Regard for All Life \& Human Health
E - Energy from the Sun
E - Ensure degradability \& No Hazards
N - New Ideas \& Different Thinking
E - Engineer for Simplicity \& Practicality
R - Recycle Whenever Possible
A- Appropriate Materials for Function
F- Fewer Auxiliary Substances \& Solvents
R- Reactions Using Catalysts
I - Indigenous Renewable Feedstocks
C- Cleaner Air \& Water
A- Avoid the Mistakes of Others

